\section{Un solo ensayo para identificar distintas especies de Leishmania}

La leishmaniasis, en sus formas clínicas principales (cutánea, cutánea difusa, visceral y secuelas dérmicas del kala-azar), es una zoonosis ampliamente difundida en zonas tropicales, donde causa una elevada mortalidad. Según la OMS, de los 1,5 a 2 millones de casos de leishmaniasis que se presentan en el mundo cada año, apenas 600000 son notificados a las autoridades sanitarias. Veintidós especies de Leishmania pueden causar enfermedad en el ser humano y no parece haber ninguna relación directa entre la especie causal y el tipo de leishmaniasis, aunque en general en zonas neotropicales Leishmania (Leishmania) chagasi se asocia más con la enfermedad de tipo visceral y Leishmania (Viannia) braziliensis con la enfermedad cutánea. Hasta ahora, los métodos de identificación descritos en la bibliografía médica son aplicables únicamente a grupos particulares de especies, de tal manera que ninguno por sí solo permite distinguir entre todos los posibles agentes causales de la enfermedad.

El deseo de encontrar nuevas sondas moleculares, raras veces descritas en la bibliografía médica como método de identificación, ha llevado a un grupo de investigadores del Instituto de Ciencias Biomédicas de la Universidad de São Paulo, Brasil, a examinar la posibilidad de efectuar una nueva prueba basada en la reacción en cadena de la polimerasa (RCP) para identificar secuencias del gen $G 6 P D$, codificador de la enzima glucosa-6-fosfatodeshidrogenasa. Los investigadores partieron de la hipótesis de que esta enzima, una de las más usadas para identificar Leishmania mediante análisis de zimodemas, muestra isoformas específicas en cada especie. La isoforma G6PD-7, por ejemplo, está presente casi exclusivamente en la especie L. (Viannia) braziliensis. El carácter polimórfico del gen les permitió a estos investigadores derivar secuencias de oligonucleótidos de cuatro especies de Leishmania que pudieron combinar con cebadores para su uso con la RCP.

La nueva prueba arrojó resultados muy útiles. Mediante ella los investigadores lograron distinguir entre parásitos de cada uno de los dos subgéneros principales de Leishmania — L. (Leishmania) y L. (Viannia)—, así como entre L. (Viannia) braziliensis y otros parásitos del subgénero L. (Viannia). Asimismo, pudieron discriminar entre Leishmania y organismos que a menudo muestran reacción cruzada con parásitos de ese género, tales como Crithidia fasciculata y Trypanosoma cruzi. Además de su especificidad, la prueba posee suficiente sensibilidad para identificar parásitos en especímenes tomados por biopsia.

Estos resultados son muy importantes porque gracias a ellos se abre la posibilidad de realizar estudios epidemiológicos en territorios que, como el del Amazonas, albergan más de una especie del subgénero Leishmania (Viannia). También se torna posible hacer estudios de seguimiento de pacientes tratados con quimioterapia antiparasitaria y evaluar su evolución clínica. (Castilho TM et al. New PCR assay using glucose-6-phosphate dehydrogenase for identification of Leishmania species. J Clin Microbiol 2003;42(2):540-546.)

\section{Nueva clasificación epidemiológica de los tipos de papilomavirus asociados con el cáncer cervicouterino}

El cáncer cervicouterino, que es el cáncer femenino que más abunda en mujeres de países en desarrollo, donde se presentan $80 \%$ de los casos en el mundo, guarda una estrecha relación con la infección por ciertos virus del papiloma humano (VPH). En 1995, la Agencia Internacional para Investigaciones sobre el Cáncer (IARC) llegó a la conclusión de que existían datos suficientes para considerar a los VPH tipos 16 y 18 como cancerígenos en seres humanos. No obstante, el riesgo específico asociado con cada uno de los más de 80 tipos conocidos de estos virus (40 de ellos detectados en el aparto genital), sobre todo con aquellos cuya prevalencia es baja, hasta ahora no se había podido dilucidar, ni tampoco había consenso acerca de cuáles de los 11 tipos que entonces se consideraban "de alto riesgo" $(16,18,31,33,35,39,45,51,52,56$ y 58) podían estar más o menos asociados con el desarrollo de cáncer cervicouterino. Esto se debe a la ausencia de criterios bien definidos que permitan llegar a una clasificación convincente del potencial oncogénico de estos virus.

Un grupo encabezado por una investigadora colombiana ha reunido los datos aportados por 11 estudios de casos y testigos efectuados en nueve países (Brasil, Colombia, España, Filipinas, Mali, Marruecos, Paraguay, Perú y Tailandia), con un 